\title{
Cytokine Removal with High Cut-Off Membrane: Review of Literature
}

\author{
Gianluca Villa a, b Jose J. Zaragoza ${ }^{a, c}$ Aashish Sharma ${ }^{a, d}$ Mauro Neria \\ A. Raffaele De Gaudio ${ }^{\text {b Claudio Ronco }}{ }^{a}$ \\ ${ }^{a}$ International Renal Research Institute of Vicenza, Vicenza, and ${ }^{b}$ Department of Health Science, Section of \\ Anesthesiology and Intensive Care, University of Florence, Florence, Italy; ' Intensive Care Unit, Hospital Español, \\ Mexico City, Mexico; d Department of Nephrology, Indraprastha Apollo Hospitals, New Delhi, India
}

\section{Key Words}

Blood purification · Systemic inflammatory syndrome .

Hemodialysis · Cytokines · High cut-off membrane

\begin{abstract}
During the last decade, blood purification therapies have been proposed as an effective therapy to control the cytokines dysregulation in systemic inflammatory syndromes. Among them, the treatment with high cut-off membranes is characterized by larger pore size and more effective clearance for middle molecular weight molecules (cytokines). In this paper, we performed a thoughtful review of the literature on HCO being used for blood purification indications in all systemic inflammation syndromes. Clinical and experimental studies show that the use of high effluent flows in a pure diffusive treatment effectively removes serum cytokines with a safe profile in albumin clearance. In clinical studies, the removal of these inflammatory mediators is associated with a significant improvement in hemodynamic condition, oxygenation indices, and organ dysfunction.
\end{abstract}

(c) 2014 S. Karger AG, Basel (c) 2014 S. Karger AG, Basel

0253-5068/14/0384-0167\$39.50/0

\section{Introduction}

Cytokines are middle molecular weight molecules having, autocrine, paracrine, and/or endocrine effects. These molecules regulate the hormonal, metabolic, and immunological responses to external (i.e., infection, trauma, etc.) or internal (i.e., ischemia, cancer, etc.) aggressions [1]. This complex regulation correlates not only with the type and extent of damage but also with the genetic characteristics that have not yet been fully understood [2]. In other words, a particular patient would be able to produce and release a vast amount of these mediators, and in some cases, overexpress them in relation to the etiological stimulus. This impairment in regulation of cytokines is recognized as a main pathophysiological mechanism in the systemic inflammatory syndromes (i.e., sepsis or severe acute pancreatitis), common among critically ill patients $[1,3,4]$.

A number of attempts have been made in the past to attenuate the clinical expression of the dysregulation through the suppression of specific mediators implicated in either inflammatory or anti-inflammatory pathways

\section{KARGER}

E-Mail karger@karger.com

www.karger.com/bpu
Gianluca Villa

Department of Health Science, Section of Anesthesiology and Intensive Care University of Florence, Largo Brambilla 3

IT-50134 Florence (Italy)

E-Mail gianlucavilla1@gmail.com 
[5]. However, those efforts failed to produce required clinical improvement due to the redundant and pleiotropic effects of the cytokines. Instead, the nonselective contemporary removal of various mediators has been recognized as the effective alternative [4]. The latter is actually able to modify both inflammatory and anti-inflammatory effects in different metabolic pathways.

During the last decade, the extracorporeal removal of cytokines has been proposed as one of the therapeutic options to reduce these overexpressed molecules. $\mathrm{Nu}$ merous theories have been offered to explain the role of this action in modulating the inflammatory pathways. The 'peak concentration hypothesis' states that by preventing the early peak of circulating molecules, these techniques are capable of preventing and modulating the clinical effects of both inflammatory and anti-inflammatory responses [4]. This extracorporeal removal reduces the serum concentration of different cytokines in the same pathways preventing its clinical manifestation ('threshold immunomodulation hypothesis') [6]. The reduction in serum concentration achieved by high volume fluid exchange treatments, which is accompanied by an increased lymphatic flow, leads to a proportional reduction in tissue cytokine concentration as mentioned in the 'mediator delivery hypothesis' [7]. Furthermore, the reduction in the circulating level of molecules could restore the concentration gradient necessary to guide the reticuloendothelial system to the main production site (i.e., the source of infection) improving the efficiency of the immune system ('cytokinetic model') [8]. Finally, a direct immune-homeostatic role has been demonstrated for some extracorporeal blood purification therapies that modulate the $H L A-D R$ expression, correlating with cell activation and interaction with some cell reproductive systems [9].

Numerous types of blood purification therapies have been described in the last few years, but none is recognized as the superior over others. Among them, the use of high cut-off membrane (HCO) is the one we believe offers more advantages.

We performed a thoughtful review of the literature on HCO being used for blood purification indications.

\section{Engineering Characteristics of High Cut-Off \\ Membrane}

The development of HCO represents one of the most recent advances in membrane technology for renal replacement therapy [10]. Their indications encompass all clinical conditions in which an effective removal of substances in the range of $20 \mathrm{kDa}$ to $50 \mathrm{kDa}$ is desired. Al- though the sieving coefficient (SC) profile differs from that observed in the physiological glomerular filtration barrier, a comparable clearance may be obtained for molecules such as myoglobin, free light chain immunoglobulins or cytokines [10].

The higher transmembrane clearance achievable with an $\mathrm{HCO}$ is mainly due to the increase in the pore size $(>0.01 \mu \mathrm{m}$, around double than a standard high-flux membrane) [11]. As a consequence, an increased cut-off is usually perceived. Generally, an SC for albumin over zero should be obtained to define a membrane as HCO. In other words, a cut-off value of at least $60 \mathrm{kDa}$ should be distinctive of these membranes.

The membrane cut-off is the mean value of the molecular weight of those molecules with an SC equal to 0.1 . Clinically it is represented by the molecular weight of the largest molecule attained for transmembrane clearance. On the other hand, HCO showed an increased retention onset, defined as the mean value of the molecular weight of those molecules with an SC equal to 0.9 , clinically represented by the molecular weight of the smallest molecule which is subjected to transmembrane retention. The higher retention onset allows to increase and maintain clearance of molecules with a lower molecular weight for longer periods of time, that is, myoglobin (18 kDa) [12], $\beta 2$-microglobulin (12 kDa) [13], and interleukin-8 (8 kDa) [14]. The adhesion of proteins to the membrane surface commonly occurs during the treatment, and this new layer ('protein cake') acts as a barrier that further affects the transmembrane clearance by means of pore occlusion. This phenomenon leads to the so-called membrane fouling. The increase in the retention onset by increasing pore size diminishes the membrane fouling effect, allowing a prolonged clearance for molecules with lower (up to 20 $\mathrm{kDa}$ ) molecular weight [10].

\section{Literature Pitfalls}

The lack of a standardized definition and classification of dialysis membranes has led to contrasting results on the clinical effect of HCO in reducing the circulating cytokines. Many terms have been utilized to categorize these membranes (i.e., high permeability, super highflux, etc.) causing major confusion to compare results. In fact, although several randomized clinical trial (RCT) and observational studies affirm to have utilized an HCO, they failed to actually express all the membrane characteristics including pore size or cut-off value. Moreover, studies often miss specifying the treatment settings as blood flow or effluent dose rendering them useless for 
Table 1. Technical characteristics and clearances observed in the main selected studies

\begin{tabular}{|c|c|c|c|c|c|c|c|c|c|c|c|}
\hline & \multirow[t]{2}{*}{ Therapy } & \multirow[t]{2}{*}{ Membrane } & \multirow{2}{*}{$\begin{array}{l}\text { Flows: } \\
\mathrm{Qb} / \mathrm{Qr} / \mathrm{Qd} \text {, } \\
\mathrm{ml} / \mathrm{min}\end{array}$} & \multicolumn{8}{|c|}{ Clearance, $\mathrm{ml} / \mathrm{min}$} \\
\hline & & & & IL-1 $\beta$ & IL-6 & IL-8 & IL-10 & IL-1ra & IL-18 & TNF- $\alpha$ & albumin \\
\hline \multirow{2}{*}{$\begin{array}{l}\text { Haase } \\
\text { et al. [14] }\end{array}$} & \multirow[t]{2}{*}{ IHD } & $\mathrm{HCO}\left(1.1 \mathrm{~m}^{2}, 60 \mathrm{kDa}\right)$ & $200 /-/ 300$ & & $9.6-14.1$ & $68.3-75.2$ & $10.5-25.5$ & & $6.5-11.5$ & & $0.8-1.9$ \\
\hline & & $\mathrm{HF}\left(1.1 \mathrm{~m}^{2}, 30 \mathrm{kDa}\right)$ & $200 /-/ 300$ & & $1.6-6.6^{\S}$ & & & & & & \\
\hline \multirow{4}{*}{$\begin{array}{l}\text { Morgera } \\
\text { et al. [32] }\end{array}$} & \multirow[t]{2}{*}{$\mathrm{CVVH}$} & \multirow[t]{2}{*}{$\mathrm{HCO}\left(1.1 \mathrm{~m}^{2}, 60 \mathrm{kDa}\right)$} & $150 /-/ 16.7$ & & $5.9-11.1^{*, \#}$ & & & $16-16.5^{*, \S}$ & & & $0.02-0.27$ \\
\hline & & & $150 /-/ 41.7$ & & $10-33.7^{*, \#}$ & & & $39.8-42.3^{*, \S}$ & & & $0.21-1.7$ \\
\hline & \multirow[t]{2}{*}{ CVVHD } & \multirow[t]{2}{*}{$\operatorname{HCO}\left(1.1 \mathrm{~m}^{2}, 60 \mathrm{kDa}\right)$} & $150 / 16.7 /-$ & & $7.1-10.3^{*, \#}$ & & & $12.5-17.3^{*, \S}$ & & & $0.02-0.36$ \\
\hline & & & $150 / 41.7 /-$ & & $16.2-26.7^{*, \#}$ & & & $22.5-32.3^{*, \S}$ & & & $0.06-0.81$ \\
\hline $\begin{array}{l}\text { Morgera } \\
\text { et al. [34] }\end{array}$ & $\mathrm{CVVH}$ & $\mathrm{HCO}\left(0.6 \mathrm{~m}^{2}, 60 \mathrm{kDa}\right)$ & $150 / 16.7 /-$ & & $12-17$ & & & & & & $0.23-1.14$ \\
\hline \multirow{2}{*}{$\begin{array}{l}\text { Morgera } \\
\text { et al. [31] }\end{array}$} & \multirow[t]{2}{*}{ CVVH } & $\mathrm{HCO}\left(1.1 \mathrm{~m}^{2}, 60 \mathrm{kDa}\right)$ & $150 /-/ 41.7$ & & $36-40$ & & & 39 & & & \\
\hline & & $\mathrm{HF}\left(1.1 \mathrm{~m}^{2}, 30 \mathrm{kDa}\right)$ & $150 /-/ 41.7$ & & $0.1-0.4^{\S}$ & & & $3.5-6.2^{\S}$ & & & \\
\hline \multirow{10}{*}{$\begin{array}{l}\text { Mariano } \\
\text { et al. [30] }\end{array}$} & \multirow[t]{6}{*}{ IHF } & \multirow[t]{3}{*}{ Type A $(\mathrm{HF})^{+}$} & $100 / 20 /-$ & $11.5-19.5$ & $8.7-13.4^{\S}$ & $4.1-9.7$ & & $10.7-16.7$ & & $9.6-16.5$ & $0.69-3.2$ \\
\hline & & & $150 / 30 /-$ & $20.4-31.5$ & $8.8-17.6$ & $7.5-20$ & & $16.8-33.7$ & & $14.2-30.8$ & $0.93-6.58^{\S}$ \\
\hline & & & $200 / 40 /-$ & $15.9-27.7$ & $11.4-22$ & $8.4-33$ & & $20.6-35.7$ & & $11.5-32.3$ & $0.91-5.86^{\S}$ \\
\hline & & \multirow[t]{3}{*}{ Type B $(\mathrm{HCO})^{+}$} & $100 / 20 /-$ & $10.9-17.8$ & $7.8-36.2^{\S}$ & $4.7-10.2$ & & $10.5-13.3$ & & $7.9-18.6$ & $1.8-6.11$ \\
\hline & & & $150 / 30 /-$ & $16.2-30$ & $9.1-20.4$ & $4.2-23.1$ & & $11.7-28.5$ & & $13.8-35.6$ & $2.6-10.8^{\S}$ \\
\hline & & & $200 / 40 /-$ & 16-26.4 & $11.7-34.7$ & $8.8-37.1$ & & $23.4-34.5$ & & $19.7-25.7$ & $3.17-10.7^{\S}$ \\
\hline & \multirow[t]{2}{*}{$\mathrm{IHD}$} & \multirow[t]{2}{*}{ Type B $(\mathrm{HCO})^{+}$} & $150 /-/ 50$ & & & & & & & & $0.57-7.02$ \\
\hline & & & $150 /-/ 83$ & & & & & & & & $0.81-8.94$ \\
\hline & \multirow[t]{2}{*}{ IHDF } & \multirow[t]{2}{*}{ Type B $(\mathrm{HCO})^{+}$} & $150 / 8.4 / 42$ & & & & & & & & $0.71-8.23$ \\
\hline & & & $150 / 8.4 / 75$ & & & & & & & & $0.91-11.12$ \\
\hline
\end{tabular}

* Significant lower clearance observed at the end of treatment. ${ }^{\S}$ Significant difference in clearance observed between groups treated with different membranes. " Significant difference in clearance among patient treated with the same therapy but different flows. ${ }^{+} \mathrm{HF}$ and HCO defined according to albumin SC, 0.05 and 0.13 , respectively.

$\mathrm{IHD}=$ Intermittent hemodialysis; CVVHD = continuous veno-venous hemodialysis; $\mathrm{CVVH}=$ continuous veno-venous hemofiltration; $\mathrm{IHF}=$ intermittent hemofiltration; IHDF = intermittent hemodiafiltration; HF = high-flux; HCO = high cut-off; $\mathrm{Qb}=$ blood flow; $\mathrm{Qr}=\mathrm{replacement}$ flow; $\mathrm{Qd}=\mathrm{di}$ alysate flow.

comparative purposes. A univocal definition of the membrane cut-off should be adopted.

To illustrate this, we identify published articles on HCO membranes using an electronic strategy. All publication types and languages were considered in a MEDLINE/PubMed search from 1965 to August 2014. We used 6 primary keywords ('high cut off, 'high cut-off, 'high cutoff, 'high permeability', 'super high flux', 'large pore') with 8 secondary ('replacement therapy', 'renal support', 'dialysis', 'filtration', 'diafiltration', 'hemodialysis', 'hemofiltration', 'hemodiafiltration') and 10 tertiary keywords ('sepsis', 'cytokine', 'inflammatory mediators', 'inflammation', 'anti-inflammation', 'systemic inflammatory response syndrome', 'compensatory anti-inflammatory response', 'SIRS', 'CARS' and 'shock').

Ninety-eight studies were obtained. Among these, 71 were excluded because they were not related to the main

Cytokine Removal with High Cut-Off Membrane issue or they lacked information about serum cytokines. Two studies were excluded for the lack of specific information about the treatment setting. Finally, 2 of them, although they declared to have used an HCO, the actual membrane cut-off was lower than $60 \mathrm{kDa}$ (table 1).

At the end, 3 case reports [15-17], 3 studies on animals [18-20], 11 in-vitro/ex-vivo studies [13, 21-30], and 6 randomized clinical trials/observational studies [14, 3135] fulfilled optimum criteria. The main results deriving from this pool constitute this review.

\section{Clinical Evidence}

\section{Effects of HCO Treatment on Cytokines}

A reduction in serum inflammatory and anti-inflammatory cytokines is common in all identified studies. 


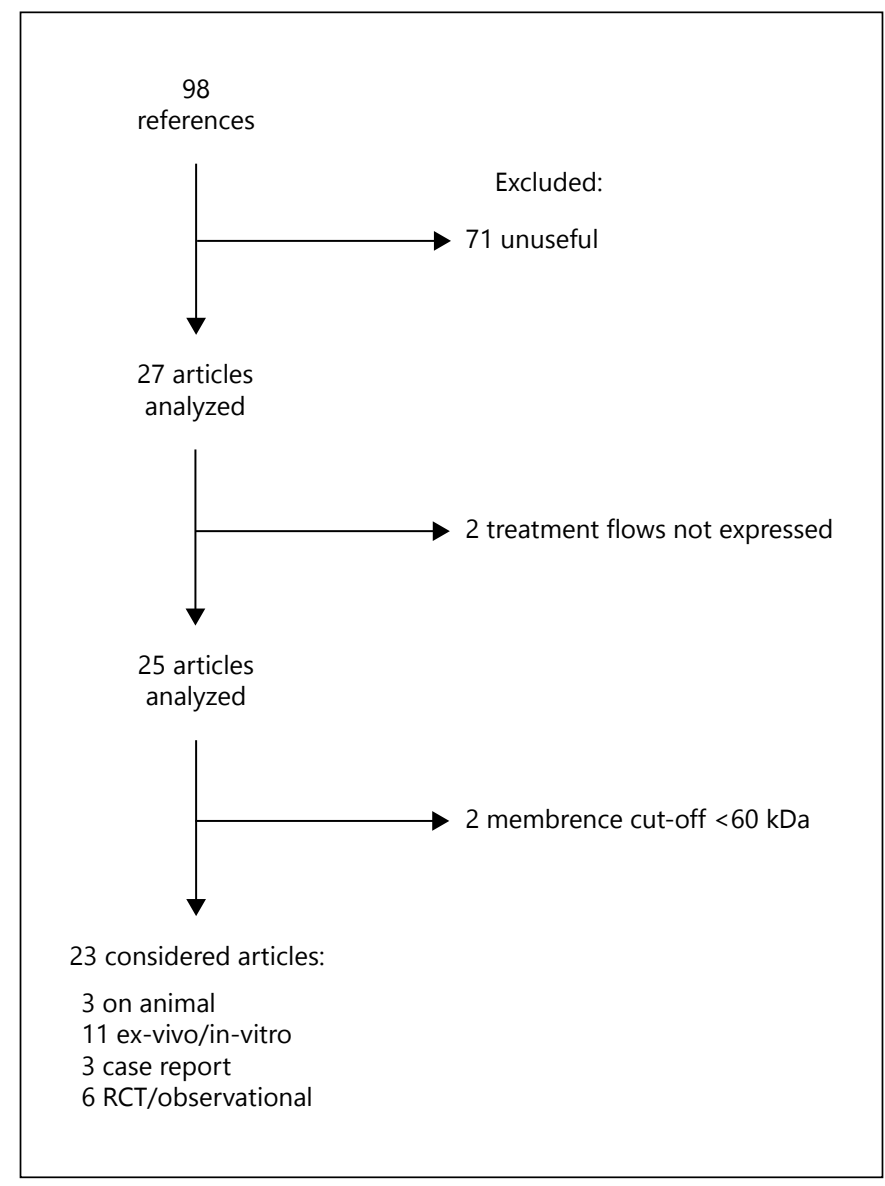

Fig. 1. Articles' selection process.

In a prospective, single-center pilot trial, Morgera et al. [34] observed an SC for IL-6 equal to 0.87 . They analyzed 16 patients with multiple organ dysfunction induced by septic shock treated with $\mathrm{HCO}$-hemofiltration for $12 \mathrm{~h}$ a day for 5 days. The mean IL-6 clearance was $12-17 \mathrm{ml} /$ min during the entire treatment. A significant reduction in the total amount of circulating IL-6, estimated by the plasma IL-6 Area Under the Curve was observed. They also found a correlation between IL- 6 concentrations in plasma and effluents [34].

An increase in cytokine clearance was observed by the same authors using $\mathrm{HCO}$ with convective and diffusive techniques. In a prospective controlled trial, they [32] randomized 24 septic patients with AKI to receive diffusive vs. convective HCO renal replacement therapy. Convective technique was shown more efficient than diffusive in reducing circulating cytokine (IL-6 and IL-1ra). An increase in the effluent rate was also recognized to increase solute clearance. Regrettably, by using convective tech- nique and increasing the effluent rate, a higher clearance for albumin was also detected.

In a double-blind, cross-over, controlled trial by Haase et al. [14] a difference in clearance properties was observed between HCO and standard high-flux membranes. They randomized 10 septic patients with AKI to $\mathrm{HCO}$ or high-flux intermittent hemodialysis. They found a significant and stable decrease in serum IL-6 concentration after 4 hours with HCO-hemodialysis. A significant difference was observed in IL- 6 concentration at the end of treatment between $\mathrm{HCO}$ and high-flux treated patients. Moreover, for IL-6, IL-8, and IL-10 a greater reduction in prefilter to postfilter plasma cytokine levels was observed during HCO compared with high-flux treatments [14].

The use of HCO in particular clinical conditions has been described. In particular, Kade et al. reported a reduction in IL-4, IL-6, IL-10, and IL-12 in a patient with multiple organ dysfunction due to sepsis and following cardiac arrest [16]. Chelazzi et al. reported the use of continuous hemodialysis with HCO membrane for severe acute pancreatitis (SAP), recording a net reduction of hematic cytokine concentration, specially of IL-6, which is recognized as one of the most important molecules in SAP pathophysiology [3].

In an experimental study performed in an animal model of ischemic fulminant hepatic failure, Detry et al. randomized fifteen pigs to a $6 \mathrm{~h}$ treatment of hemofiltration with HCO (cut-off $80 \mathrm{kDa}$ ). TNF- $\alpha$ concentrations below the detecting capability were obtained for the treated group, whereas the mean values of $94.5 \pm 19.2 \mathrm{pg} / \mathrm{ml}$ were observed for the control group. Additionally, lower levels of IL-10 were observed in treated swine than in the control group at the end of treatment $(11.8 \pm 3.2 \mathrm{vs}$. $18.6 \pm 5.8 \mathrm{pg} / \mathrm{ml}$, respectively) [19].

Lastly, a significant reduction in proclacitonin (PCT; molecular weight $13 \mathrm{kDa}$ ) serum concentration was observed during the treatment with HCO. Although this effect could be related to the anti-inflammatory effect of the treatment, a direct transmembrane clearance was also observed (SC of 0.45), decreasing the clinical accuracy of PCT as biomarker of sepsis [36]. However, considering the role of PCT as a mediator of tissue transmigration and activation of monocytes [37], its active extracorporeal removal could also retain a therapeutic effect.

\section{Effects of HCO Treatment on Albumin}

$\mathrm{HCO}$ hemofilters have a risk of albumin loss. In the study conducted by Morgera et al. [34], albumin loss was particularly high in the initial phase of the treat- 
ment. However, this phenomenon rapidly declined over time probably due to the clotting and clogging of the membrane. An SC equal to 0.04, 0.02, and 0.01 was observed at $0.5,2$, and 12 hours of treatment. The authors reported a protein loss of nearly $8 \mathrm{~g} /$ day with a convective dose of $1 \mathrm{l} / \mathrm{h}$. A mean value of $140 \mathrm{ml}$ of substitution plasma (either fresh frozen plasma or human albumin) was administered to maintain stable plasma albumin levels.

In the above-mentioned randomized trial by Haase et al. [14], they prescribed blood and dialysate flows of 200 and $300 \mathrm{ml} / \mathrm{min}$, respectively. A significant reduction in serum albumin was observed among the patients treated with $\mathrm{HCO}$ with respect to high-flux membranes and higher levels of albumin loss in the effluent $(7.7 \mathrm{~g}$ vs. $1 \mathrm{~g}$, respectively, $\mathrm{p}<0.01)$. However, the HCO albumin clearance fell from 1.9 to $0.9 \mathrm{ml} / \mathrm{min}$ after $4 \mathrm{~h}$ of treatment [14].

In a pure convective technique, the increase in effluent rate significantly increases the albumin loss. In a randomized controlled study, albumin clearance significantly increased from $0.27 \mathrm{ml} / \mathrm{min}$ with an effluent rate of $1 \mathrm{l} / \mathrm{h}$ to 1.7 with $2.5 \mathrm{l} / \mathrm{h}$ [32] (table 1) after $30 \mathrm{~min}$ of treatment. Similar finding were observed in diffusive techniques. An increase in the clearance from 0.36 to 0.81 was observed increasing the dialysate rate from $1 \mathrm{l} / \mathrm{h}$ to $2.5 \mathrm{l} / \mathrm{h}$ [32]. At this moment, after interpreting these results, an increase in the effluent flow in a pure dialytic treatment is the best suited option of therapy in order to increase the cytokine clearance preventing excessive albumin loss.

In 2005, Mariano et al. performed an in vitro study comparing the albumin clearance in hemofiltration for $6 \mathrm{~h}$. They observed an increase in albumin clearance comparing HCO versus high-flux membrane [30]. In an exvivo study, blood from healthy volunteers incubated with endotoxin was run in an HCO membrane (cut-off 100 $\mathrm{kDa}$, area $1.2 \mathrm{~m}^{2}$ ) [26]. Convective and dialytic treatments were interchanged during the procedure as well as the effluent rate. The author suggested that by increasing the ultrafiltration rate from 1 to $3 \mathrm{l} / \mathrm{h}$ a higher clearance for IL-1 ra, IL-6 and TNF- $\alpha$ was obtained with a significant concomitant increase in albumin loss. Similar findings were observed with pure dialytic treatment. Comparing hemofiltration with hemodialysis in the $1 \mathrm{l} / \mathrm{h}$ mode revealed a higher clearance for TNF- $\alpha$ and albumin. The advantages of hemofiltration lost their statistical significance when the procedures were switched to the $3 \mathrm{l} / \mathrm{h}$ mode. Only albumin clearance still remained statistically higher in the hemofiltration group [26]. Analogous results were obtained by Detry et al. A significant reduction in albumin serum concentration was observed in swine treated with $\mathrm{HCO}$ (cut-off $80 \mathrm{kDa}$ ) during the treatment and lower levels were observed after 6 hours of treatment in this group with respect to the control group (18.66 \pm 1.4 vs. $22 \pm 1.75 \mathrm{~g} / \mathrm{l}, \mathrm{p}<0.05)$ [19].

\section{Effects of HCO on Coagulation Factors}

Taking into account the molecular weight of Protein $\mathrm{C}$ $(62 \mathrm{kDa})$, Protein $S(69 \mathrm{kDa})$, and Antithrombin III (AT III, $60 \mathrm{kDa}$ ), a reduction in these molecules during a treatment with $\mathrm{HCO}$ is expected.

In septic patients treated by intermittent $\mathrm{HCO}$ hemofiltration, coagulation factors were not affected by the treatment. Stable values were found for plasma AT III, factor II $(69 \mathrm{kDa})$, protein $\mathrm{C}$, protein $\mathrm{S}$, and factor VIII $(265 \mathrm{kDa})$ from baseline to $12 \mathrm{~h}$ and after $72 \mathrm{~h}$ of hemofiltration. There was no need for the substitution during the entire study [34].

\section{Effects on Hemodynamics and MOD}

A prospective clinical trial showed a significant reduction in APACHE II and multi-organ dysfunction score (MODS) during the treatment with HCO. These facts were not significantly different between patients treated with convective or diffusive techniques [32]. In a randomized controlled trial on 30 septic patients with AKI, HCO hemofiltration was associated with reduced SAPS II score at $48 \mathrm{~h}$ of treatment with respect to baseline. Moreover, SAPS II scores of HCO patients were statistically lower when compared to high-flux hemofiltration treated patients [31]. The reduction in the scores of organ dysfunction was mainly related to an improvement in hemodynamic parameters, with a stable decrease of vasopressor requirement in treated patients [31]. The authors showed a significant reduction in norepinephrine dose in $\mathrm{HCO}$ with respect to patients treated by high-flux hemofiltration. Similar results were obtained by Haase et al. with an increase in mean arterial pressure and a stable decrease in norepinephrine requirement in patients treated with intermittent hemodialysis with HCO [14]. Morgera et al. observed a significant improvement in patients' cardiovascular condition during intermittent hemofiltration with HCO. An increase in cardiac output (from 5.9 to $8.4 \mathrm{l} / \mathrm{min}$ ) and mean arterial pressure $(77.5-80 \mathrm{~mm} \mathrm{Hg})$ were observed at $12 \mathrm{~h}$ of treatment, with a concomitant reduction in norepinephrine requirement $(0.26$ to $0.19 \mu \mathrm{g} / \mathrm{kg} / \mathrm{min})$ [34]. Comparable findings have been shown in non-septic patients treated with $\mathrm{HCO}$ membranes, with an improvement in hemodynamic parameters and in indices of oxygenation [3]. 


\section{Conclusions}

The lack of a standardized definition of dialysis membranes has led to contrasting results on the clinical effect of HCO. An SC for albumin over zero should be used to define a membrane as HCO (cut-off value of at least of $60 \mathrm{kDa}$ ).

A reduction in serum inflammatory and anti-inflammatory cytokines is common in HCO treatment. Convective technique and increase in effluent rates have shown to be more efficient in reducing circulating cyto- kines in relation to higher clearance of albumin. An increase in the effluent flow in a pure diffusive treatment is the best-suited option of a therapy in order to increase the cytokine removal and to reduce excessive albumin loss.

An improvement in the hemodynamic parameters and indices of oxygenation has been shown in septic and non-septic patients treated with $\mathrm{HCO}$ membranes. The use of HCO in particular clinical conditions, other than sepsis (as severe acute pancreatitis or retinoic acid syndrome), should be considered and explored.

\section{References}

$\checkmark 1$ Honore PM, Joannes-Boyau O, Boer W, Collin V: High-volume hemofiltration in sepsis and SIRS: current concepts and future prospects. Blood Purif 2009;28:1-11.

2 Angus DC, van der Poll T: Severe sepsis and septic shock. N Engl J Med 2013;369:840851.

-3 Chelazzi C, Giugni D, Giannoni C, Villa G, De Gaudio AR: Use of continuous venovenous hemodiafiltration with a high cutoff membrane in a patient with severe acute pancreatitis. J Nephrol 2012;2:78-81.

-4 Ronco C, Bonello M, Bordoni V, Ricci Z, D'Intini V, Bellomo R, et al: Extracorporeal therapies in non-renal disease: treatment of sepsis and the peak concentration hypothesis. Blood Purif 2004;22:164-174.

5 Connolly AB, Vernon DR: Manipulations of the metabolic response for management of patients with severe surgical illness: review. World J Surg 2000;24:696-704.

-6 Honoré PM, Matson JR: Extracorporeal removal for sepsis: acting at the tissue level the beginning of a new era for this treatment modality in septic shock. Crit Care Med 2004; 32:896-897.

7 Di Carlo JV, Alexander SR: Hemofiltration for cytokine-driven illnesses: the mediator delivery hypothesis. Int J Artif Organs 2005; 28:777-786.

8 Rimmelé T, Kellum JA: Clinical review: blood purification for sepsis. Crit Care 2011;15:205.

$\checkmark 9$ Peng Z, Singbartl K, Simon P, Rimmele T: Blood purification in sepsis: a new paradigm. Contrib Nephrol 2010;165:322-328.

10 Boschetti-de-Fierro A, Voigt M, Storr M, Krause B: Extended characterization of a new class of membranes for blood purification: the high cut-off membranes. Int J Artif Organs 2013;36:455-463.

11 Gondouin B, Hutchison CA: High cut-off dialysis membranes: current uses and future potential. Adv Chronic Kidney Dis 2011;18 180-187.

12 Premru V, Kovac J, Buturovic-Ponikvar J, Ponikvar R: High cut-off membrane hemodiafiltration in myoglobinuric acute renal fail- ure: a case series. Ther Apher Dial 2011;15: 287-291.

13 Uchino S, Bellomo R, Morimatsu H, Goldsmith D, Davenport P, Cole L, et al: Cytokine dialysis: an ex vivo study. ASAIO J 2002;48: 650-653.

14 Haase M, Bellomo R, Baldwin I, Haase-Fielitz A, Fealy N, Davenport P, et al: Hemodialysis membrane with a high-molecular-weight cutoff and cytokine levels in sepsis complicated by acute renal failure: a phase 1 randomized trial. Am J Kidney Dis 2007;50:296304.

15 Madelaine T, Page M, Prothet J, Ber CE, Crozon J, Allaouchiche B, et al: Super high-flux continuous hemodialysis in septic shock: a case report. Nephrol Ther 2013;9:497-500.

16 Kade G, Wiśniewska M, Lubas A, Rzeszotarska A, Korsak J: The treatment of septic shock with continuous venovenous hemodialysis using high cut-off dialyzer in patient after immediate circulatory arrest. Przegl Lek 2013; 70:698-700.

17 Gong D, Ji D, Zhang K, Huang X, Huang G, $\mathrm{Xu}$ B, et al: Endotoxemia after high cutoff hemodialysis for treatment of patient with multiple myeloma can be prevented by using ultrapure dialysate: a case report. Hemodial Int 2013;17:618-623.

18 Kline J, Gordon BE, Williams C, Blumenthal S, Watts JA, Diaz-Buxo J: Large-pore hemodialysis in acute endotoxin shock. Crit Care Med 1999;27:588-596.

19 Detry O, Janssen N, Cheramy-Bien JP, Cavalier E, Defraigne JO, Delanaye P, Lambermont B: Effects of large-pore hemofiltration in a swine model of fulminant hepatic failure. Artif Organs 2012;36:981-987.

20 Lambermont B, Delanaye P, Dogné JM, Ghuysen A, Janssen N, Dubois B, et al: Largepore membrane hemofiltration increases cytokine clearance and improves right ventricular-vascular coupling during endotoxic shock in pigs. Artif Organs 2006;30:560-564.

21 Yumoto M, Nishida O, Moriyama K, Shimomura Y, Nakamura T, Kuriyama N, et al: In vitro evaluation of high mobility group box 1 protein removal with various membranes for continuous hemofiltration. Ther Apher Dial 2011;15:385-393.

22 Haase M, Bellomo R, Baldwin I, Haase-Fielitz A, Storr M, Krause B, et al: The effect of three different miniaturized blood purification devices on plasma cytokine concentration in an ex vivo model of endotoxinemia. Int J Artif Organs 2008;31:722-729.

23 Delanaye P, Lambermont B, Dogné JM, Dubois B, Ghuysen A, Janssen N, et al: Confirmation of high cytokine clearance by hemofiltration with a cellulose triacetate membrane with large pores: an in vivo study. Int J Artif Organs 2006;29:944-948.

24 Lee WC, Uchino S, Fealy N, Baldwin I, Panagiotopoulos S, Goehl H, et al: Super high flux hemodialysis at high dialysate flows: an ex vivo assessment. Int J Artif Organs 2004;27: 24-28.

25 Uchino S, Bellomo R, Goldsmith D, Davenport $\mathrm{P}$, Cole L, Baldwin I, et al: Cytokine removal with a large pore cellulose triacetate filter: an ex vivo study. Int J Artif Organs 2002; 25:27-32.

26 Morgera S, Klonower D, Rocktaschel J, Haase $\mathrm{M}$, Priem F, Ziemer S, et al: TNF- $\alpha$ elimination with high cut-off haemofilters: a feasible clinical modality for septic patients? Nephrol Dial Transplant 2003;18:1361-1369.

27 Uchino S, Bellomo R, Goldsmith D, Davenport P, Cole L, Baldwin I, et al: Super high flux hemofiltration: a new technique for cytokine removal. Intensive Care Med 2002;28:651655.

28 Bordoni V, Bolgan I, Brendolan A, Crepaldi C, Gastaldon F, D'intini V, et al: Caspase-3 and -8 activation and cytokine removal with a novel cellulose triacetate super-permeable membrane in an in vitro sepsis model. Int J Artif Organs 2003;26:897-905.

29 Dominik A, Stange J, Pfensig C, Borufka L, Weiss-Reining H, Eggert M: Reduction of elevated cytokine levels in acute/acute-onchronic liver failure using super-large pore albumin dialysis treatment: an in vitro study. Ther Apher Dial 2014;18:347-352. 
30 Mariano F, Fonsato V, Lanfranco G, Pohlmeier R, Ronco C, Triolo G, et al: Tailoring highcut-off membranes and feasible application in sepsis-associated acute renal failure: in vitro studies. Nephrol Dial Transplant 2005;20: 1116-1126.

- 31 Morgera S, Haase M, Kuss T, Vargas-Hein O, Zuckermann-Becker H, Melzer C, et al: Pilot study on the effects of high cutoff hemofiltration on the need for norepinephrine in septic patients with acute renal failure. Crit Care Med 2006;34:2099-2104.

- 32 Morgera S, Slowinski T, Melzer C, Sobottke $\mathrm{V}$, Vargas-Hein O, Volk T, et al: Renal replacement therapy with high-cutoff hemofilters: impact of convection and diffusion on cytokine clearances and protein status. Am J Kidney Dis 2004;43:444-453.
33 Morgera S, Haase M, Rocktaschel J, Bohler $\mathrm{T}$, von Heymann C, Vargas-Hein $\mathrm{O}$, et al: High permeability haemofiltration improves peripheral blood mononuclear cell proliferation in septic patients with acute renal failure. Nephrol Dial Transplant 2003;18:25702576.

34 Morgera S, Rocktäschel J, Haase M, Lehmann C, von Heymann C, Ziemer S, et al: Intermittent high permeability hemofiltration in septic patients with acute renal failure. Intensive Care Med 2003;29:1989-1995.
35 Morgera S, Haase M, Rocktäschel J, Böhler T, Vargas-Hein O, Melzer C, et al: Intermittent high-permeability hemofiltration modulates inflammatory response in septic patients with multiorgan failure. Nephron Clin Pract 2003; 94:c75-c80

-36 Caldini A, Chelazzi C, Terreni A, Biagioli T, Giannoni C, Villa G, et al: Is procalcitonin a reliable marker of sepsis in critically ill septic patients undergoing continuous veno-venous hemodiafiltration with 'high cut-off membranes (HCO-CVVHDF)? Clin Chem Lab Med 2013;51:e261-e263.

37 Matera G, Quirino A, Giancotti A, Pulicari MC, Rametti L, Rodríguez ML, et al: Procalcitonin neutralizes bacterial LPS and reduces LPS-induced cytokine release in human peripheral blood mononuclear cells. BMC Microbiol 2012;12:68. 